\title{
Are Peri-operative Inflammatory Markers Useful in Predicting Post-operative Ileus?
}

\author{
Jung Ho Park \\ Department of Internal Medicine, Kangbuk Samsung Hospital, Sungkyunkwan University College of Medicine, Seoul, Korea
}

Article: Peri-operative inflammatory marker as a predictive factor for prolonged post-operative ileus after gastrectomy for gastric cancer

Kim Y, Kim YM, Kim JH, Youn YH, Kim JW, Park H

(J Neurogastroenterol Motil 2021;27:588-595)

Post-operative ileus (POI) is an impairment of gastrointestinal (GI) motility that inevitably occurs after abdominal surgery. The main symptoms of this disease include nausea and vomiting, bloating, and the inability to eat orally due to delayed passage of the GI tract. POI is one of the main reasons for slowing patients' recovery and increasing the length of hospital stay after surgery. ${ }^{1}$ In addition, the economic burden of treatment for patients due to POI is also very large. According to data from the United States, hospitalization for coded POI was substantially more costly and longer than hospitalization for non-coded POI. Total annual costs attributed to managing POI were $\$ 1.46$ billion. $^{2}$

At least 3 major mechanisms are suggested to be involved in the development of POI; neurogenic, inflammatory, and pharmacological mechanisms. Splanchnic, rather than vagal afferents, are predominantly activated during abdominal surgery and lead to decreased peristalsis during and shortly after (up to 3 hours) the operation, ${ }^{4}$ and other neural pathways are activated during abdominal surgery, according to the degree of pain of the nociceptive stimulus. Surgical manipulation of the intestine also activated macrophages to secrete inflammatory mediators, including nitric oxide, prostaglandins, and reactive oxygen intermediates. ${ }^{5,6}$ Also, this intestinal inflammation caused by bowel manipulation results in primary afferent activation, initiating subsequent inhibitory motor reflexes to the gut, and leading to post-operative intestinal gut dysfunction. ${ }^{7}$ Lastly, intake of opioids as analgesics can complicate and prolong POI. ${ }^{8}$

In this issue of the Journal of Neurogastroenterology and Motility, peri-operative inflammatory markers were investigated as predictive factors for prolonged POI after gastrectomy for gastric cancer. ${ }^{9}$ C-reactive protein (CRP) level, neutrophil to lymphocyte ratio (NLR), and platelet to lymphocyte ratio were compared between the control group and prolonged POI group, and preoperative NLR ( $P=0.014)$, Post-operative day (POD) 1 NLR $(P=0.019), \operatorname{POD} 3 \mathrm{CRP}(P=0.004)$, and POD3 NLR $(P=$ 0.008 ) were independent risk factors for PPOI. Based on these results, the authors recommended the use of therapeutic agents such as prokinetics or prophylactic antibiotics targeting the varied aspects of the systemic inflammatory response.

For sure, evaluation of NLR is an effective method for predicting overall and disease-free survival in gastric cancer patients submitted to curative resection. ${ }^{10}$ A high NLR reflects both strengthened neutrophil-induced inflammatory response and weakened

Received: September 6, 2021 Revised: None Accepted: September 17, 2021

(.) This is an Open Access article distributed under the terms of the Creative Commons Attribution Non-Commercial License (http://creativecommons. org/licenses/by-nc/4.0) which permits unrestricted non-commercial use, distribution, and reproduction in any medium, provided the original work is properly cited.

*Correspondence: Jung Ho Park, MD Department of Internal Medicine, Kangbuk Samsung Hospital, Sungkyunkwan University College of Medicine, 29 Saemunan-ro, Jongno-gu, Seoul 03181, Korea

Tel: +82-2-2001-2059, Fax: +82-2-2001-2485, E-mail: pjho3@hotmail.com 
lymphocyte-mediated antibacterial response of cancer patients, and NLR is a more objective indicator of a patient's condition than CRP in this study. However, in most studies of CRP and NLR for predicting the prognosis in cancer patients, they are independent factors for the survival of cancer patients, and their role in predicting tumor response and survival is more enhanced when used in combination. ${ }^{11,12}$ If these 2 factors were analyzed together in this study, it would have been a more meaningful indicator.

As the author said, this study had several limiting factors. These include its retrospective design and neglecting narcotic drug use. In addition, clinical factors such as whether there were other infectious diseases such as pneumonia and how severe the pain was were not considered. Also, factors such as operation methods, time, and postoperative complications were not included for analysis. Nevertheless, this is the first study to study the usefulness of CRP and NLR for predicting post-operative ileus in gastric cancer patients, and these results can be used meaningfully in treating patients.

\section{Financial support: None.}

\section{Conflicts of interest: None.}

\section{References}

1. Baig MK, Wexner SD. Postoperative ileus: a review. Dis Colon Rectum 2004;47:516-526.

2. Goldstein JL, Matuszewski KA, Delaney CP, et al. Inpatient economic burden of postoperative ileus associated with abdominal surgery in the United States. P AND T 2007;32:82.
3. Bauer AJ, Boeckxstaens GE. Mechanisms of postoperative ileus. Neurogastroenterol Motil 2004;16(suppl 2):54-60.

4. Zittel TT, Lloyd KC, Rothenhöfer I, Wong H, Walsh JH, Raybould HE. Calcitonin gene-related peptide and spinal afferents partly mediate postoperative colonic ileus in the rat. Surgery 1998;123:518-527.

5. Cicalese L, Rastellini C, Rao AS, Stanko RT. Pyruvate prevents mucosal reperfusion injury, oxygen free-radical production, and neutrophil infiltration after rat small bowel preservation and transplantation. Transplant Proc 1996;28:2611.

6. Kalff JC, Schraut WH, Billiar TR, Simmons RL, Bauer AJ. Role of inducible nitric oxide synthase in postoperative intestinal smooth muscle dysfunction in rodents. Gastroenterology 2000;118:316-327.

7. Schwarz NT, Kalff JC, Türler A, et al. Prostanoid production via COX-2 as a causative mechanism of rodent postoperative ileus. Gastroenterology 2001;121:1354-1371.

8. Bauer AJ, Sarr MG, Szurszewski JH. Opioids inhibit neuromuscular transmission in circular muscle of human and baboon jejunum. Gastroenterology 1991;101:970-976.

9. Kim Y, Kim YM, Kim JH, Youn YH, Kim JW, Park H. Peri-operative inflammatory marker as a predictive factor for prolonged post-operative ileus after gastrectomy for gastric cancer. J Neurogastroenterol Motil 2021;27:588-595.

10. Templeton AJ, McNamara MG, Šeruga B, et al. Prognostic role of neutrophil-to-lymphocyte ratio in solid tumors: a systematic review and meta-analysis. J Natl Cancer Inst 2014;106:djy124.

11. Oh BS, Jang JW, Kwon JH, et al. Prognostic value of C-reactive protein and neutrophil-to-lymphocyte ratio in patients with hepatocellular carcinoma. BMC cancer 2013;13:78

12. Tomita M, Shimizu T, Ayabe T, Nakamura K, Onitsuka T. Elevated preoperative inflammatory markers based on neutrophil-to-lymphocyte ratio and C-reactive protein predict poor survival in resected non-small cell lung cancer. Anticancer Res 2012;32:3535-3538. 